\title{
Um caso de parasitismo por Rhabditis sp em criança natural de Goiânia, Goiás, Brasil
}

\author{
A case of parasitism by Rhabditis sp in a child \\ from Goiânia, Goiás, Brazil \\ Dulcinéa M. Barbosa Campos'ㄹ, José Luiz de B. Araújo', \\ Maria Cristina M. Vieira', Fátima Damasceno² \\ e Alverne Passos Barbosa ${ }^{1}$
}

\begin{abstract}
Resumo Relata-se um caso de parasitismo por Rhabditis sp em criança com cinco meses de idade procedente do Estado de Goiás, Brasil. O quadro clínico mostrou inicialmente diarréia com fezes líquidas esverdeadas e posteriormente sanguinolentas. O exame parasitológico de fezes revelou a presença de larvas e adultos de Rhabditis sp. Após o uso de thiabendazole houve melhora no quadro clínico e cura. Os autores chamam atenção para a importância de se estabelecer o diagnóstico diferencial entre Strongyloides e Rhabditis.
\end{abstract}

Palavras-chaves: Rhabditis sp. Verme de vida livre. Diarréia. Parasitismo.

Abstract We report a case of parasitism by Rhabditis sp in a five-month-old child, from Goiás State, Brazil. He had a history of diarrhea with liquid and green faeces which later became bloody. Parasitological examination revealed the presence of larvae and adult female of Rhabditis $\mathrm{sp}$. We used thiabendazole in this case after which the child improved. The authors suggest a better differential diagnostic between ${ }^{1}$ Strongyloides and Rhabditis.

Key-words: Rhabditis sp. Free living worm. Diarrhea. Parasitism.

O gênero Rhabditis Dujardin, 1845 compõe-se de vermes que vivem habitualmente em matéria orgânica em decomposição, terra úmida, em água doce ou salgada. Algumas espécies são parasitas, sobretudo de insetos e ocasionalmente de vertebrados ${ }^{12}$.

Há na literatura casos de parasitismo humano por várias espécies do gênero e muitas vezes o agente etiológico é simplesmente citado como Rhabditis sp.
Na oportunidade, relata-se um caso de criança que apresentou distúrbio abdominal cuja etiologia foi inicialmente atribuída à infecção bacteriana e estrongiloidíase. Um exame coproscópico realizado por essa equipe de trabalho demonstrou o encontro de larvas e adultos de Rahbditis sp e não Strongyloides stercoralis como pensou-se anteriormente.

\section{RELATO DO CASO}

Paciente CCG, masculino, 5 meses de idade. Após ingerir mel de abelhas quando estava a passeio na cidade de Rio Verde, Goiás, Brasil, apresentou diarréia com fezes líquidas esverdeadas que tornaram-se sanguinolentas e depois sangue vivo com tenesmo e febre baixa. Posteriormente, houve oligúria crescente. Tratamento domiciliar por oito dias com solução de eletrólitos fisiologicamente equilibrada, pronta para uso, Saccharomyces boulardii, caulim e pectina sem melhora. Exame parasitológico de fezes negativo e hemograma que revelou anemia com desvio à esquerda com $19 \%$ de bastonetes. Nesta época foi introduzido neomicina oral, de 12/12 horas, por dois dias. Após 10 dias de tratamento domiciliar foi internado com quadro clínico de desidratação leve, com intensa assadura perianal. O paciente respondeu bem à hidratação oral por meio de sonda e farelo de arroz, sem antibióticoterapia. No $15^{\circ}$ dia de evolução começou apresentar febre contínua de $38,5^{\circ} \mathrm{C}$. No exame de urina tipo I havia $32 \%$ de piócitos/campo, flora bacteriana moderada.

\footnotetext{
1. Departamento de Microbiologia, Imunologia, Parasitologia e Patologia do Instituto de Patologia Tropical e Saúde Pública da Universidade Federal de Goiás. 2. Departamento de Pediatria da Faculdade de Medicina da Universidade Federal de Goiás, Goiânia, GO.

Endereço para correspondência: Prof ${ }^{a}$ Dulcinéa M. Barbosa Campos. R. Delenda Rezende de Mello s/n Esq. Iª Avenida. Setor Universitário, 74605-050 Goiânia, GO.

e-mail:dmcampos@iptsp.ufg.br

Recebido para publicação em 21/6/2001.
} 
Cultura de fezes revelou Escherichia coli enteropatogênica clássica. Continuou evoluindo com febre, e apesar de introduzida cefazolina sódica, no $20^{\circ}$ dia da doença começou a apresentar pico febril de $40^{\circ} \mathrm{C}$, seguido por hipotermia acentuada, palidez intensa e cianose. Suspeita de choque endotóxico. Novo hemograma revelou $22 \%$ de bastonetes e hemoglobina $9,4 \mathrm{~g} \%$. Continuou evoluindo mal e então foram introduzidos amicacina e ceftrisiona quando passou a apresentar melhora clínica estabilizando a temperatura. No exame de fezes foram identificadas larvas Strongyloides stercoralis. Um terceiro exame coproscópico, desta vez, realizado pela equipe que ora relata o caso, revelou presença de ovos, larvas rabditiformes e fêmeas adultas identificados como Nematoda, família Rhabdiasidae, gênero Rhabditis

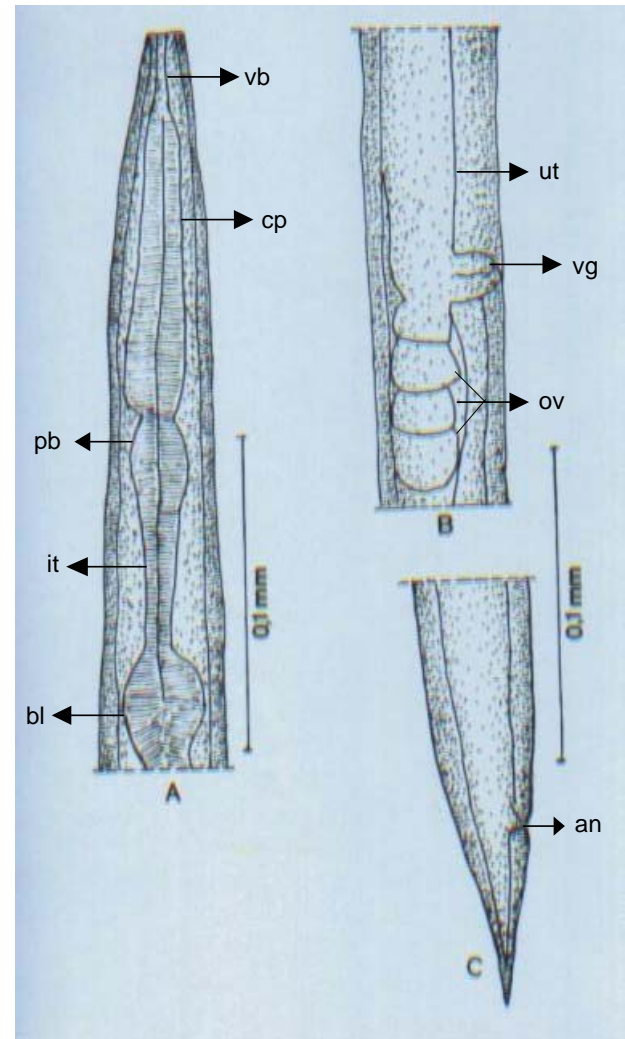

Figura 1 - Fêmea de Rhabditis sp. A: extremidade anterior (vb, vestíbulo bucal; cp, corpo; $p b$ pseudobulbo; it, istmo; bl, bulbo). B: genitália (vg vagina; ut, útero; ov, ovos). C: extremidade posterio (na, ânus) tendo em vista, as seguintes características morfológicas:

Adultos: cutícula lisa sem ornamentações, extremidade anterior romba. Vestíbulo bucal relativamente longo com paredes duplas. Esôfago constituído de corpo, bulbo médio esofagiano, ístmo e bulbo posterior. Cauda longa e afilada. Fêmeas medindo $0,6 \mathrm{~mm}$ de comprimento por $0,03 \mathrm{~mm}$ de largura, esôfago apresentando $0,1 \mathrm{~mm}$ de comprimento, distância ânus ponta da cauda $0,045 \mathrm{~mm}$ e vulva localizada na região média do corpo ou seja à $0,3 \mathrm{~mm}$ da extremidade anterior (Figura 1).

Larvas rabdtiformes: apresentam vestíbulo bucal e esôfago, morfologicamente, semelhantes aos dos vermes adultos, comprimento total aproximadamente $200 \mu \mathrm{m}$; intestino simples, reto e ânus (Figura 2).

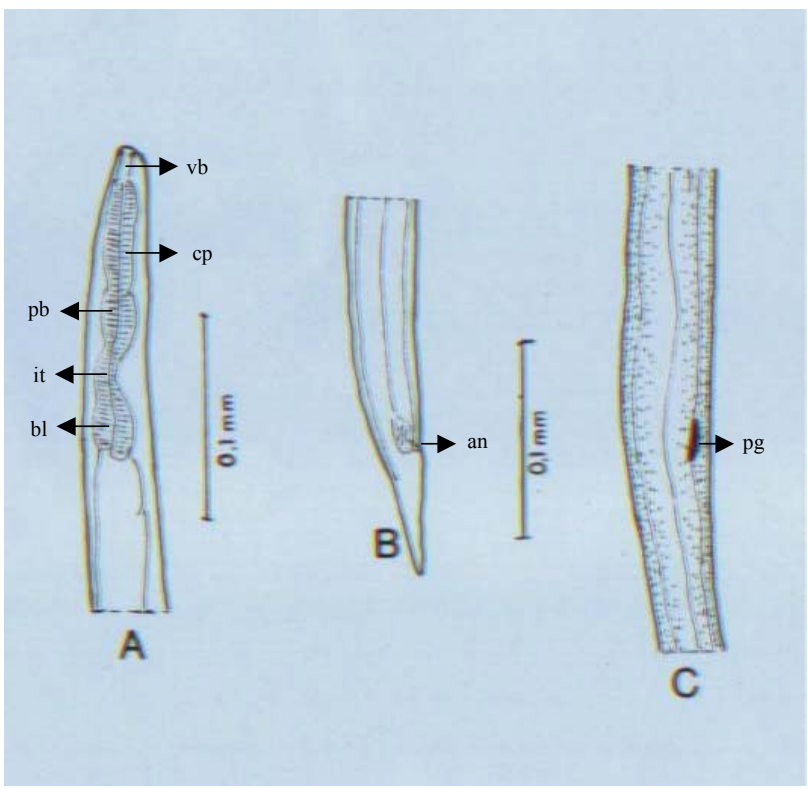

Figura 2 - Larva rabditóide de Rhabditis sp. A: extremidade anterior anterior (vb vestíbulo bucal; $c p$ corpo; $p b$, pseudobulbo; it, istmo

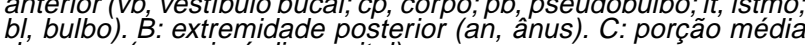
do corpo (pg, primórdio genital).

Após a identificação do helminto introduziu-se thiabendazole, oportunidade, em que houve melhora do quadro clínico e cura. O desaparecimento dos sintomas, após uso da droga, sugere que o nematoda do gênero Rhabditis tenha sido o agente etiológico do quadro clínico apresentado pelo paciente.

\section{DISCUSSÃO}

Entre os parasitos de mamíferos da ordem Rhabdiasidea há a família Strongyloididae na qual encontra-se inserido o gênero Strongyloides e família Rhabdiasidae com o gênero Rhabditis ${ }^{914}$. Nas duas famílias há espécies que são mantidas na natureza apenas através de gerações de vida livre, há espécies com préadaptação ao parasitismo, há parasitos facultativos e parasitos obrigatórios ${ }^{12}$. No gênero Rhabditis, a maioria das espécies vive em matéria orgânica em decomposição sendo comuns no solo, água parada e frutas em decomposição. Por essa razão, alcançam com muita facilidade o corpo de grandes animais. Os aparelhos 
reprodutor, digestivo e respiratório destes animais são particularmente susceptíveis à entrada dos vermes através do contato com o solo. Em tais localizações, tornam-se parasitos facultativos durante um pequeno espaço de tempo ou simplesmente, são eliminados através do corpo dos mesmos ${ }^{14}$. No homem, de maneira semelhante ao que ocorre com os animais, representantes do gênero Rhabditis podem ser encontrados vivos em tecidos ulcerados, no lumen de vários órgãos, em fezes recém eliminadas e eventualmente na vagina ${ }^{46}$.

Espécies dos gêneros Strongyloides e Rhabditis, são muito semelhantes do ponto de vista morfológico. Além do mais, cada um destes gêneros apresenta um grande número de espécies. No gênero Strongyloides são conhecidas 52 espécies que parasitam aves, répteis, anfíbios e mamíferos. Critérios para identificação de espécies nesse gênero foi objeto de muita polêmica em parasitologia. Muitas espécies eram registradas à medida que novos hospedeiros iam sendo encontrados infectados ${ }^{3}$.

Fato semelhante aplica-se ao gênero Rhabditis. Novas espécies vão sendo descritas à medida que novos casos humanos vão sendo relatados. Associados à diarréia humana há Rhabditis faecalis, Rhabditis usuii, Rhabditis elongata, Rhabditis inermis e Rhabditis hominis. Na vagina humana e tracto urinário são relatados $R$ habditis pellio, Rhabditis axei. Esta última espécie foi encontrada em aves mantidas em gaiolas de um laboratório de parasitologia do Egito. A peculiaridade de predomínio do ciclo de vida livre nas espécies do gênero Rhabditis, resultou em insucesso tentativas de inoculação experimental do helminto em outras aves do laboratório, após passagem pelo intestino deste hospedeiro ${ }^{5}$.

Neveu-Lemaire ${ }^{12}$ mencionou seis espécies, afirmando que três destas podem ocorrer no homem: $R$. pellio Schneider, 1866 cujas larvas vivem encistadas na cavidade geral dos anelídeos e adultos podem acidentalmente parasitar a espécie humana, localizando-se na vagina. Tem distribuição geográfica descrita para Europa. Rhabditis niellyi Blanchard, 1855 descrito na Inglaterra, em um jovem de 14 anos, que apresentou pápulas principalmente nos membros inferiores, com uma ou mais larvas presentes no líquido dos tecidos infectados. $R$. hominis Kobaiashi, 1914 foi descrito no Japão em crianças de 10 a 14 anos de idade e na Austrália, apresentando os indivíduos parasitados, grande número de vermes em todos os estádios de desenvolvimento em diarréias recentes.

Okabe e Higuchi ${ }^{13}$ obtiveram exemplares em uma placenta humana em caso de aborto cuja espécie não foi identificada.

Morisita et al $^{11}$ identificaram vermes obtidos de cultura de fezes humanas como $R$. elongata e $R$. inermis.
Morisita $^{10}$ fizeram uma revisão sobre o gênero Rhabditis oportunidade em algumas espécies foram mencionadas. Citam Watanabe ${ }^{15}$ que relatou o encontro de $R$. faecalis obtido de cultura de fezes humanas em um asilo em Tóquio e $R$. usuii encontrada em fezes humanas em um caso similar. Citam também Akagi ${ }^{2}$ que encontrou exemplares do mesmo gênero em fezes humanas, embora a espécie não tenha sido identificada.

Ahn et al $^{1}$ descreveram cinco casos de parasitismo por Rhabditis sp em crianças de uma escola rural na Coréia. Os autores encontraram uma prevalência 0,54\% em fezes de 925 crianças examinadas mencionando que deveria tratar-se de parasitismo facultativo, uma vez que após três semanas as larvas não foram mais encontradas.

Feng e $\mathrm{Li}^{7}$ descreveram $R$. axei na urina de dois chineses e sugeriram que os vermes tenham sido adquiridos através de matéria orgânica em decomposição. $R$. axei foi também relatado na urina de uma senhora africana que vivia na região de Mashonaland onde folhas eram utilizadas para banho vaginal. $R$. pellio foi encontrado na vagina de humanos cuja urina continha larvas, pus e hemácias. Rhabditis foi também descrito como parasito facultativo no centro industrial de Don (Rússia) devido a intimidade de humanos com vermes nos túneis de mineração. Rhabditis strongyloides foi recuperado de lesões cutâneas de cães e um caso foi registrado em uma criança de 11 anos de idade com lesões na pele dos membros inferiores e tronco por brincar e eventualmente dormir com um cão. $\mathrm{O}$ animal tinha sofrido perda de pelo no abdome e morrido uma semana antes do exame das lesões da criança ${ }^{6}$.

Ainda no Japão Eldridge ${ }^{6}$ relata três casos de infecção do trato urinário humano devido a Rhabditis sp. Os pacientes tinham 10, 28 e 49 anos de idade. Todos os três pacientes apresentaram quilúria, hematúria e edema nos membros inferiores. Suas urinas mostraram turbidez com aumento do número de hemácias, leucócitos e células epitelióides. Larvas e vermes quase adultos de Rhabditis foram encontrados na urina de todos os três casos.

A falta de critérios consistentes na classificação destes vermes origina, com muita freqüência, apenas a citação Rhabditis sp. Apresentam um ciclo evolutivo semelhante ao ciclo de vida livre de Strongyloides. Após a fertilização pelos machos, as fêmeas eliminam ovos que liberam larvas rabditóides. Estas se alimentam, sofrem mudas larvárias, provavelmente quatro mudas como a maioria dos nematoda, originando novos vermes adultos. Não há larvas filariformes no ciclo. A falta de informação sobre a possibilidade de infecção humana por Rhabditis e pouca atenção no exame parasitológico de fezes levam a falsos resultados no diagnóstico, tal como ocorreu no caso ora relatado. 


\section{REFERÊNCIAS BIBLIOGRÁFICAS}

1. Ahn YK, Chung PR, Lee KT. Rhabditis sp infected cases in rural school children. Korean Journal of Parasitology 23: 1-6, 1985.

2. Akagi K. On a new species of Rhabditis found in Ainu race of Hokkaido. Chugai lji Shinpo 1126: 151-156, 1927. In: Morisita K, Komiya Y, Matsubayashi H (eds) Progress of Medical Parasitology in Japan. Meguro Parasitological Museum, Tokyo, p. 753, 1964.

3. Campos DMB. Strongyloides cebus Darling,1911. Confirmação de espécie. Revista de Patologia Tropical 14: 173-219, 1985

4. Dogiel VA. General Parasitology. Oliver \& Boyd, London, p. 516, 1964.

5. El-Azazy OM, El-Gawady HM, Nada MS. The occurrence of Rhabditis (Rhabditella) axei in the faeces of a chicken in Egypt. Journal of Helminthology 62 : 219-220, 1988.

6. Eldridge B. Human urinary tract infection caused by Rhabditis sp. Microbiology Digest 10: 202-203, 1993.

7. Feng LC, LI F. Two human cases of urinary tract infection with Rhabditella axei. Peking Natural History Bulletin 18:195-202,1950.

8. Goldsmid JM. Rhabditis (Rhabditella) axei in urine of an African in Rhodesia. Journal of Helminthology 12: 305-308,1967.
9. lamaguti S. Systema Helminthum-The nematodes of Vertebrates. Interscience Publishers, New York, London, 1961.

10. Morisita T. Classification of the nematodes of the genus Rhabditis found in human stool. In: 14 $4^{\text {th }}$ Nippon Kiseushiu Gakkai Nishinippon Taikai Kiji, p. 47, 1958.

11. Morisita K, Komiya Y, Matsubayashi H. Progress of Medical Parasitology in Japan. Meguro Parasitological Museum. Tokyo, 1964.

12. Neveu-Lemaire M. Traité D’Helminthologie Médicale et Veterinaire. Vigot Frères, Paris, 1936.

13. Okabe K, Higuchi M. On Rhabditis sp obtained from the placenta of a miscarriage case. Eisei Dobutsu 4 (special Number): 75-78,1954.

14. Schmidt GD, Roberts LS. Foundations of Parasitology. Mosby Company, London, 1981.

15. Watanabe $\mathrm{H}$. On a species of Rhabditis occurring in the culture of eggs found in stool of a patients. Dobutsugaku Zasshi, 32: 389-395,1920. In: Morisita K, Komiya Y, Matsubayashi H (eds) Progress of Medical Parasitology in Japan. Meguro Parasitological Museum. Tokyo, p. 753, 1964. 